\title{
Mercado Internacional da Soja: Modelando os Efeitos dos Custos das Transações e das Barreiras Comerciais
}

\author{
International Soybean Market: Modelling the Effects \\ of Transaction Costs and Trade Barriers
}

\author{
Maria Inês Caetani ${ }^{\mathrm{a}}$ \\ Augusto Mussi Alvima
}

\begin{abstract}
Resumo: Este estudo analisa os impactos dos custos das transações e das barreiras comerciais no mercado internacional da soja. Para atingir tal objetivo, utiliza-se um modelo de equilíbrio parcial formulado como um problema de complementaridade mista, o qual permite a construção de cenários alternativos. São definidos três cenários: no primeiro, eliminam-se os custos das transações comerciais; no segundo, retiram-se as barreiras tarifárias e os subsídios; e, no terceiro, é simulado um choque de demanda de $20 \%$. Os resultados mostram que a eliminação dos custos das transações comerciais resulta em um aumento na produção de soja no Brasil, Argentina e China e um maior consumo nos Estados Unidos, China, União Europeia e resto do mundo. No cenário de livre-comércio, observa-se que as mudanças, em termos de produção e consumo, são reduzidas, o que reflete as características das políticas adotadas pelos principais países produtores e consumidores. Os resultados do cenário de livre-comércio favorecem os produtores brasileiros e argentinos em detrimento dos produtores americanos. A simulação do choque de demanda mostra que o Brasil (exportador) e os países da União Europeia (importador) são os únicos que apresentam um maior incremento no consumo do que na produção. Por fim, com base nos cenários analisados, os maiores ganhos para os produtores de soja são esperados para o terceiro cenário, considerando-se as expectativas de incremento no consumo de soja e derivados (farelo, óleo e biodiesel).
\end{abstract}

Palavras-chave: Barreiras comerciais. Custos das transações comerciais. Problema de complementaridade mista. Soja.

\begin{abstract}
This paper analyzes the main effects of the costs of trade transactions and trade barriers on the international soybean market. A partial equilibrium model formulated as a mixed complementarity problem is used to provide the simulation of alternative scenarios. Three scenarios are defined: in the first, the trade transactions costs are eliminated; in the second, a free trade scenario (no tariff and subsidies); and the third, it is simulated a demand shock. The results show that the elimination of trade transaction costs causes an increase in soybean production in Brazil, Argentina and China and an increase in consumption in the United States, China, UE and the Rest of World. In the free trade scenario, it is observed small changes in terms of production
\end{abstract}

a Pontifícia Universidade Católica do Rio Grande do Sul (PUCRS), Escola de Negócios, Programa de Pós-Graduação em Economia (PPGE). Porto Alegre, Rio Grande do Sul, Brasil. 
and consumption, reflecting the characteristics of the trade policies adopted by the major producer and consumer countries. The results of the free trade scenario show gains for Brazilian and Argentine producers and present losses for US producers. The demand shock simulation shows that Brazil (exporter) and EU countries (importer) are the only ones that have a greater increase in consumption than in production. Finally, based on the scenarios analyzed, the largest gains for soybean producers are expected for the third scenario, considering the increase in the consumption of soybean and derivatives (meal, oil and biodiesel).

Keywords: Trade barriers. Trade transaction costs. Mixed complementarity problem. Soybeans.

JEL Classification: Q13; Q17; Q18.

\section{Introdução}

A relação positiva entre comércio e expansão da atividade econômica tem estimulado acordos de livre-comércio desde a segunda metade do século XX. Contudo, muitos países continuam mantendo políticas protecionistas, especialmente quando se trata de produtos agrícolas, intervindo, regulando os mercados e estimulando as atividades econômicas através de restrições a livre circulação de capitais, mão de obra e mercadorias.

O contexto das barreiras inclui uma série de restrições que geram custos adicionais ao comércio internacional, que reúnem, por exemplo, além das tarifas e subsídios, custos associados a roubo, suborno, contrabando, perdas de mercadorias e questões de logística, crédito e litígios. De acordo com Arbix (2007), os litígios entre países junto à Organização Mundial do Comércio (OMC), com vistas a contestar as restrições às importações, exigem um período longo para solução de controvérsias e requer gastos com recursos humanos e materiais inerentes a cada processo. Também, importantes na formação dos custos, são os financiamentos necessários para participação do mercado, incluindo custos de preparação de documentos e contratos, de monitoramento dos empréstimos, de gerenciamento de risco, gastos cobrados pelas instituições financeiras ou taxas de arbitragem. ${ }^{1}$

A infraestrutura de transporte e a logística também são importantes na formação dos custos das transações comerciais no mercado internacional. Supõe-se que, quanto menos eficiente um sistema, maiores são os custos. Uma medida de desempenho dos serviços pode ser os custos de transportes e o tempo gasto para levar a

$1 \quad$ Atividade no mercado financeiro de commodities que consiste em vender mercadorias em uma praça por um preço maior que o da compra em outra. A arbitragem pode ser, por exemplo, no mercado de commodities, como trigo e soja (SANDRONI, 2008). A arbitragem gera custos como, por exemplo, comissões e/ou spreads (RABELO; JUNIOR; IKEDA, 2004). 
mercadoria da zona de produção até o ponto de embarque para o exterior. Deficiências que acarretam atrasos de chegada ao porto de destino podem repercutir no atraso de outros processos ou, até mesmo, em todos os procedimentos necessários para a exportação, resultando em custos adicionais (LIMAO; VENABLES, 2001).

O tempo que as mercadorias permanecem em trânsito, que é desde a saída da área produtora até a liberação no país importador, é fundamentalmente crítico, em especial para países em desenvolvimento. A liberação dos documentos no momento do despacho aduaneiro, de acordo com Pontes, Carmo e Porto (2009), é potencialmente um problema, como no caso do Brasil, em que os atrasos iniciam na chegada ao porto, com a formação de filas de espera formadas pela escassa infraestrutura nos portos, até a falta de armazéns e de locais para estacionamento de caminhões.

Supõe-se que há uma grande variedade de custos adicionais no mercado internacional, mas boa parte não são observáveis e, por isso, são difíceis de mensurar. Entretanto, a sua ocorrência pode interferir nos resultados e na avaliação dos efeitos de políticas comerciais.

Nesse sentido, o objetivo deste estudo é analisar os efeitos no comércio internacional de soja em grão frente às mudanças nos custos das transações comerciais, barreiras comerciais e demanda. A soja em grão é o produto escolhido para a análise por ser uma das mercadorias mais comercializadas internacionalmente e com perspectiva de elevação do consumo em função do aumento na demanda de seus subprodutos, óleo, farelo e biocombustíveis.

O desenvolvimento do estudo deve responder às seguintes questões: qual é a influência dos custos das transações comerciais nas principais regiões produtoras e consumidoras de soja no mundo? Quais os efeitos das barreiras comerciais no mercado internacional da soja? Qual é o efeito de um choque de demanda de $20 \%$ ?

Para tanto, utiliza-se um modelo de equilíbrio parcial formulado como um problema de complementaridade mista (PCM), no qual é feita a inclusão dos custos das transações e das barreiras comerciais, além da construção de cenários alternativos. Para se testar os impactos, são construídas três simulações: eliminação dos custos de transação comercial, mantendo-se constantes as tarifas e os subsídios; eliminação das tarifas e dos subsídios (livre-comércio), mantendo-se os custos de transação; e simulação de um choque de demanda de $20 \%$ sobre o consumo de soja. O período de referência utilizado são os anos de 2009 a 2011.

Por se tratar de negociação de um produto agrícola, o mercado de soja envolve riscos e incertezas relacionados com barreiras não tarifárias, como, por exemplo, os atrasos nas fronteiras em função dos requisitos relativos aos controles sanitários e fitossanitários que tendem a ser maiores em países com maior deficiência no sistema de infraestrutura e logística. Com base nisso, a contribuição deste trabalho (metodológica e empírica) está na inclusão de uma variável ao modelo PCM, que representa os custos das transações comerciais não computados como custo de transporte, tarifas e subsídios. 
O artigo está organizado em mais quatro seções, além desta introdução: a segunda apresenta o mercado internacional da soja, políticas comerciais e gargalos; a terceira descreve a metodologia utilizada com a inclusão dos custos das transações comerciais no modelo; a quarta exibe os resultados analisados; e, por fim, a quinta traça as considerações finais.

\section{Mercado Internacional da Soja, Políticas Comerciais e Gargalos}

De acordo com informações da Food and Agriculture Organization of the United Nations (FAOSTAT, 2014) e UN Comtrade (2013), os três principais produtores de soja no mundo são os Estados Unidos, o Brasil e a Argentina. Já o maior consumidor é a China, que demanda mais da metade do grão comercializado no mundo. Os Estados Unidos são os maiores produtores da soja, com uma oferta anual média de 88,739 milhões de toneladas no período $2009-2011$, ou $35,56 \%$ do grão produzido no mundo. O Brasil fica em segundo lugar com 66,972 milhões de toneladas e $26,84 \%$ de market share e a Argentina, em terceiro, com $17,71 \%$ de participação e 44,171 milhões de toneladas em média no mesmo período. A União Europeia (UE) ${ }^{2}$ e a China são os países com menor produção entre os países selecionados, com 1,141 milhões de toneladas, ou 0,46\% de market share, e 14,838 milhões de toneladas, ou 5,95\% de participação, respectivamente (ver Tabela 1).

Tabela 1 - Produção, consumo e exportações líquidas da soja em mil toneladas para as regiões selecionadas (2009-2011)

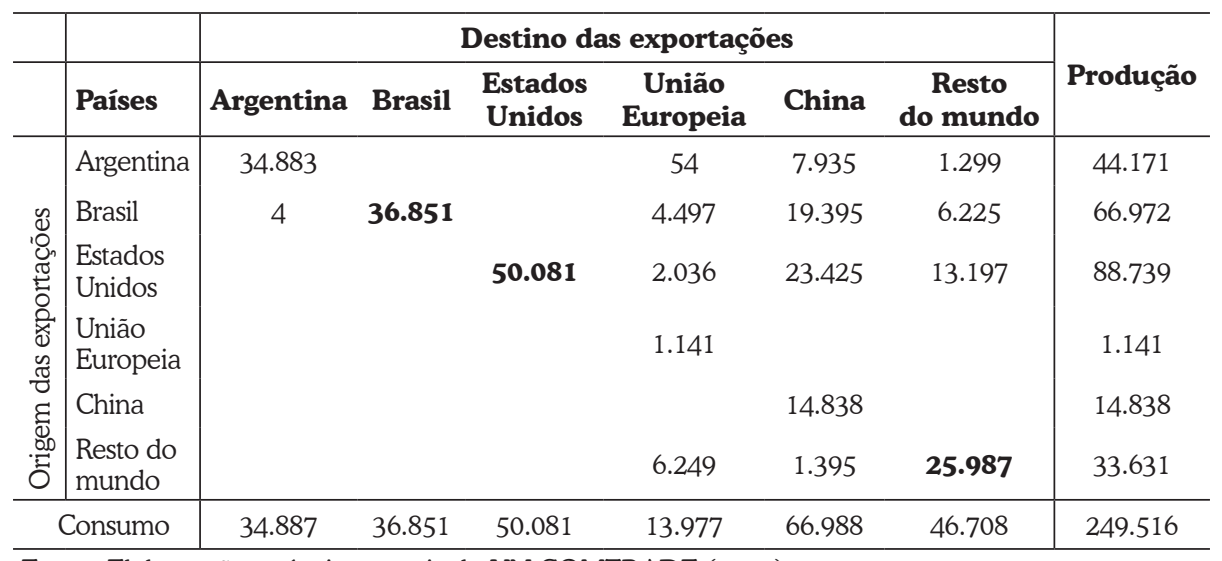

Fonte: Elaboração própria a partir de UN COMTRADE (2013).

2 A União Europeia corresponde à união de 28 países da Europa, conforme a classificação da Faostat: Áustria, Bélgica, Bulgária, Croácia, Chipre, República Checa, Dinamarca, Estônia, Finlândia, França, Alemanha, Grécia, Hungria, Irlanda, Itália, Letônia, Lituânia, Luxemburgo, Malta, Holanda, Polônia, Portugal, Romênia, Eslováquia, Eslovênia, Espanha, Suécia e Reino Unido. 
A China, porém, consome 66,988 milhões toneladas, ou $26,85 \%$ da produção mundial (FAOSTAT, 2014), sendo que a maior parte da soja importada é direcionada para a indústria de processamento do óleo e do farelo, que são consumidos para uso interno. Do total do óleo consumido, apenas 12\% é importado, e do farelo, apenas 0,68\%. Já a UE consome o menor volume do grão (13,977 milhões de toneladas, ou $5,61 \%$ do consumo mundial) porque importa os produtos já industrializados da soja, além de consumir outras oleaginosas, em especial a canola. O grupo importa aproximadamente $32 \%$ do óleo consumido e $71 \%$ do farelo (USDA, 2011).

A maior parte das importações de grão in natura da China é proveniente dos Estados Unidos, Brasil e Argentina. O Brasil exportou para a China $28,96 \%$ da sua produção no período analisado, 6,71\% para a UE e 9,30\%, para os países do resto do mundo. O Brasil consumiu 55,02\% do total produzido, sendo o maior consumidor depois dos Estados Unidos, que demandou 56,44\% do que produz internamente. A maior parte da soja americana ( $26,40 \%$ da produção) destina-se à China, o restante vai para a UE $(2,29 \%)$ e para os países do RM (14,87\%).

A Argentina, dentre os maiores produtores de soja, é o país que exporta a menor quantidade de soja em grão para China, $17,96 \%$ do seu total produzido. Isso ocorre porque a maior parte da produção, 78,95\%, é consumida internamente nas indústrias de esmagamento. Da produção de óleo e de farelo, $64 \%$ e $94 \%$, respectivamente, são comercializadas no mercado mundial. A consolidada agroindústria de soja argentina faz do país o maior mercado exportador de óleo e farelo do mundo. A exportação de soja em grão, óleo e farelo da Argentina está sujeita a diferentes tarifas de exportação. O diferencial nas alíquotas de exportação (DTE), aplicado até 2015 , equivale a $20 \%$ para os derivados (óleo e farelo) e 32\% para a soja em grão. Conforme a Tabela 2 , os subsídios concedidos à produção de soja na Argentina são reduzidos, cerca de US $\$ 1,0$ por tonelada. Esse recurso é destinado exclusivamente a pagamentos sobre o uso de insumos.

Tabela 2 - Valor da produção e do consumo e subsídios concedidos ao mercado da soja por países selecionados: média de 2009 a 2011

\begin{tabular}{lccccc}
\hline Descrição & $\begin{array}{c}\text { Estados } \\
\text { Unidos }\end{array}$ & Argentina & Brasil & China & $\begin{array}{c}\text { União } \\
\text { Europeia }\end{array}$ \\
\hline $\begin{array}{l}\text { I. Valor produção (mil US\$) } \\
\text { II. Valor consumo (mil US\$) }\end{array}$ & $\begin{array}{l}40.287 .156 \\
22.736 .774\end{array}$ & 18.507 .649 & 28.463 .266 & 7.270 .620 & 547.693 \\
\hline $\begin{array}{l}\text { III. Transferências em mil US\$ } \\
\begin{array}{l}\text { A. Suporte baseado sobre a } \\
\text { produção }\end{array}\end{array}$ & 1.290 .362 & 67.860 & 294.679 & 1.396 .652 & 3.184 \\
$\quad \begin{array}{l}\text { A1. Suporte aos preços de } \\
\text { mercado (MPS) }\end{array}$ & 0,063 & 0,0 & 31.825 & 0,0 & 3.184 \\
$\begin{array}{l}\text { A2. Pagamentos baseados } \\
\quad \text { sobre a produção }\end{array}$ & 8.063 & 0,0 & 0,0 & 1.396 .652 & 0,0 \\
$\begin{array}{l}\text { B. Pagamentos baseados sobre } \\
\text { o uso dos insumos }\end{array}$ & 0,0 & 67.860 & 262.853 & 0,0 & 0,0 \\
\hline
\end{tabular}




\begin{tabular}{lccccc}
\hline Descrição & $\begin{array}{c}\text { Estados } \\
\text { Unidos }\end{array}$ & Argentina & Brasil & China & $\begin{array}{c}\text { União } \\
\text { Europeia }\end{array}$ \\
\hline $\begin{array}{l}\text { C. } \text { Pagamento baseado em } \\
\text { recursos necessários à } \\
\text { produção da soja } \\
\quad \text { consumidos dentro do } \\
\text { ciclo operacional }\end{array}$ & 1.282 .299 & 0,0 & 0,0 & 0,0 & 0,0 \\
\hline $\begin{array}{l}\text { IV. Transferências à produção } \\
\text { (US\$ } \$ \text { ) }\end{array}$ & 15,0 & 1,0 & 4,0 & 0,0 & 3,0 \\
$\begin{array}{l}\text { V. Transferências ao consumo } \\
\text { (US } \$ \text { t })\end{array}$ & 0,0 & 0,0 & 0,0 & 21,0 & 0,0 \\
\hline
\end{tabular}

Fonte: Organização para a Cooperação e Desenvolvimento Econômico (2013).

Nota: A classificação de transferências utilizada neste estudo é a Single commodity transfers (SCT), referente a repasses calculados por produto agrícola, que, nesse caso, é específico para a soja em grão. Os valores foram convertidos em dólar e referem-se às médias anuais do período analisado neste estudo.

A UE aplica tarifas de importação sobre o óleo e farelo de 3,2\%, enquanto a soja em grão não é tarifada. A China, por sua vez, tarifa a importação do grão em $3 \%$, o farelo em $5 \%$ e o óleo em $9 \%$. As tarifas de importação mais elevadas, para os produtos com maior valor agregado, protegem as indústrias de processamento chinesas e europeias, ao mesmo tempo que contribuem para fortalecer as exportações brasileiras de soja in natura em comparação às exportações de óleo e farelo (RODRIGUES; BURNQUIST; COSTA, 2011).

A China não beneficia seus produtores com nenhum tipo de programa de empréstimos. O consumidor chinês é subsidiado a partir das transferências ao contribuinte, chamado de suporte a preços de mercado. O valor monetário bruto anual transferido decorre de políticas que alteram os preços no mercado interno, criando um diferencial entre os preços domésticos e internacionais que representam cerca de US\$21 por tonelada de soja. No caso da eu, os subsídios são exclusivamente vinculados a produção e representam cerca de US $\$ 3$ por tonelada (ver Tabela 2).

O Brasil também aplica tarifas de importação de US $\$ 0,08$ por quilograma do grão (o mesmo valor é aplicado pela Argentina), protegendo a produção doméstica da soja in natura. Já os Estados Unidos não aplicam tarifas para soja e derivados, mas adotam políticas de subsídios que totalizam US\$ 4 por tonelada de soja. Os programas são o pagamento baseado em recursos necessários à produção de soja consumidos dentro do ciclo operacional ${ }^{3}$ e pagamentos baseados na produção. ${ }^{4}$ Estes também são adotado pelo Brasil e a UE. O país mais beneficiado

3 São empréstimos realizados com base na média dos níveis de colheita dos agricultores quando a receita fica abaixo dos níveis de rendimentos de anos anteriores e abaixo dos preços de mercado. Não há limite pelo valor da produção, e as taxas são variáveis (OECD, 2013). do e o pagamento efetuado, cujo saldo tem como base o menor valor entre a taxa de empréstimo 
por esse tipo de transferência é o Brasil, onde os pagamentos baseados no uso de insumos ${ }^{5}$ são os mais relevantes (ver Tabela 2).

Já os Estados Unidos, apesar de não aplicarem tarifas de importação para a soja, concedem cerca de US $\$ 15$ por tonelada ao produtor anualmente (ver Tabela 2). Os subsídios americanos distorcem os preços de soja no comércio internacional. De acordo com Figueiredo et al. (2010), uma redução de 60\% na média anual dos subsídios americanos pode provocar uma queda de 5,73\% na produção e 2,82\% na exportação dos Estados Unidos e elevar a produção e a exportação brasileiras em 3,80\% e 3,27\%, respectivamente.

Os efeitos das barreiras comerciais somam-se aos dos gargalos existentes na infraestrutura de transporte e logística e aos das barreiras técnicas. Em 2004, a China embargou a soja brasileira pela presença em quantidades de fungicida no grão acima do limite permitido. O embargo durou aproximadamente dois meses e gerou perdas aos exportadores brasileiros, que foram obrigados a reduzir os preços da soja para não perderem o carregamento (FERNANDES et al., 2005).

As más condições da infraestrutura e logística brasileira também são formadoras de custos. As estradas rurais não possuem pavimentação e, para levar a soja até o porto, é preciso percorrer rodovias em estados péssimo ou ruim, que, além de acarretar maiores custos devido à manutenção dos veículos e o maior consumo de combustível, ainda elevam os gastos em função do maior tempo de viagem (PONTES et al., 2009).

A intermodalidade de transporte é uma saída para reduzir custos, mas, por outro lado, também pode se tornar uma fonte geradora de custos adicionais, pois o maior manuseio do produto envolve falhas de execução humana e materiais (PONTES et al., 2009; OJIMA; YAMAKAM, 2005). De acordo com Caixeta Filho e Soares (1997), na movimentação da carga durante a troca de transportes pode ocorrer perda física de até $1 \%$ no preço do produto. Um dos principais motivos são os descuidos no descarregamento e carregamento.

A falta de armazéns nas fazendas também é um problema, pois impede o planejamento dos períodos para a comercialização das safras, obrigando os agricultores a escoarem sua produção imediatamente após a colheita. Nos portos, a soja também se depara com a falta de postos de armazenagem e de estacionamento para os caminhões, que gera congestionamentos, atrasa os embarques e aumenta o tempo de espera dos navios (GIOVINE; CHRIST, 2010).

A hipótese é de que existe, ainda, uma série de outros custos, como de informação, arbitragem, roubo, perdas de mercadorias no processo de armazenamento, entre outros. Este estudo avalia a existência de tais custos de forma agrega-

do dia, dada pelo governo e a Daily posted county prices (PCP). PCP, por sua vez, é o preço de mercado do produto menos o custo de transporte entre o país exportador e o mercado de destino (OECD, 2013).

5 Refere-se a empréstimos operacionais baseados no uso de insumos para estimular a produção agrícola. No Brasil, são voltados principalmente à agricultura familiar. 
da, pois o modelo não permite desagregá-los. Os dados observados referentes ao mercado foram utilizados para a obtenção das estimativas e testes de validação do modelo, conforme é apresentado a seguir.

\section{Problema de Complementaridade Mista (PCM)}

O modelo de otimização descrito utiliza uma formulação apresentada na forma de um PCM, conforme proposto por Rutherford (1995, 2002), Ferris e Munson (2000) e Bishop, Nicholson e Pratt (2001), e já utilizado por Alvim (2003), Alvim e Waquil (2004), Nolte, Buysse e Huylenbroeck (2011) e Oliveira e Silveira (2013). É um modelo estático de equilibrio espacial que pressupõe produtos homogêneos e considera a tecnologia, as preferências e o crescimento populacional como variáveis exógenas.

O modelo leva em consideração as funções de oferta e demanda de cada produto em cada região, os custos de transporte e a presença de barreiras ao comércio, conduzindo à estimação das quantidades produzidas e consumidas, dos fluxos comerciais e dos níveis de preços em equilíbrio. O PCM consiste em um sistema de equações simultâneas (lineares ou não) apresentadas na forma de desigualdades, as quais são derivadas a partir das funções de oferta e demanda dos produtos considerados em cada uma das regiões analisadas. O PCM é equivalente às condições de Karush-Kuhn-Tucker (KKT) do problema de maximização da função net social pay-off (NSP), ${ }^{6}$ necessárias e suficientes para atingir um ponto de máximo do valor da função NSP, o que, por sua vez, implica a obtenção do equilíbrio em todos os mercados e em todas as regiões. Entretanto, o PCM tem a vantagem em relação aos demais modelos de equilíbrio parcial de permitir a incorporação de tarifas, quotas-tarifárias e subsídios com mais facilidade ao modelo.

O conjunto das equações apresentadas a seguir corresponde ao PCM e representa as condições que permitem obter os preços (preço-sombra), as quantidades produzidas e consumidas e os fluxos comerciais entre as regiões, levando em consideração as tarifas e subsídios implementados nos mercados.

$$
\begin{array}{ll}
\varphi_{i} \geq 0, & \left(\sum_{j}^{J} X_{i, j}-q_{i}^{s}\right) \cdot \varphi_{i}=0, \forall i, j \\
\lambda_{j} \geq 0, & \left(q_{j}^{d}-\sum_{i}^{I} X_{i, j}\right) \cdot \lambda_{j}=0, \forall i, j
\end{array}
$$

6 Samuelson (1952) mostra que o equilíbrio de mercado pode ser alcançado a partir da maximização da função de net social pay-off (NSP), obtida a partir da soma dos excedentes dos produtores e dos consumidores, conforme resgatado por Alvim (2010). 


$$
X_{i, j} \geq 0, \quad\left(\lambda_{j}-\left(\varphi_{i}-S_{i}+t_{i, j}\right) .\left(1+\operatorname{tar}_{i, j}\right)\right) \cdot X_{i, j}=0, \forall i, j
$$

Considerando-se a primeira equação, observa-se que $\varphi_{i}$ é uma variável complementar à expressão, que restringe a soma das exportações da i-ésima região para a j-ésima região $\left(X_{i, j}\right)$ ao total produzidas na região $i\left(q_{i}^{s}\right)$ e que representa o preço-sombra na região produtora i. Em outras palavras, sempre que o preço-sombra associado à produção daquele bem na região $i$ for maior que zero, o termo entre parênteses na equação 1 deve necessariamente ser igual a zero. Isso implica que a soma dos fluxos da região $i$ para todas as regiões (inclusive para ela própria, ou seja, produção para consumo na região mais as exportações) deve ser igual à quantidade produzida na região.

Da mesma forma, a segunda equação apresenta uma variável $\lambda_{j}$ complementar à expressão que restringe a soma das importações da j-ésima região oriundas da i-ésima região $\left(X_{i, j}\right)$ ao total consumidas naquela região $j\left(q_{j}^{d}\right)$ e que representa o preço-sombra na região consumidora $j$. Nesse caso, sempre que o preço-sombra associado ao consumo daquele bem na região j for maior que zero, o termo entre parênteses na equação 2 deve ser necessariamente igual a zero, o que implica que a quantidade consumida na região $j$ deve ser igual à soma dos fluxos de comércio para essa região j oriundos de todas as regiões (inclusive dela própria).

A equação 3 determina os fluxos comerciais entre as regiões associados aos diferenciais de preços e levando em consideração os custos de transporte $\left(t_{i, j}\right)$, subsídios $\left(S_{i}\right)$ e tarifas $\left(\operatorname{tar}_{i, j}\right)$. Essa equação implica, no caso em que os fluxos comerciais de uma determinada região $i$ para uma região j sejam maiores do que zero, que o preço do produto na região consumidora j será resultado da combinação do preço na região produtora $i$, dos subsídios concedidos, dos custos de transporte da região $i$ para j e da tarifa imposta sobre as importações originárias da região i. Se não houver comércio, é porque o preço internalizado do produto importado é maior do que o preço no mercado doméstico.

Ao modelo de convergência das três equações do PCM, apresentado anteriormente, é incluída uma quarta equação para se estimar os custos das transações comerciais e possibilitar a calibração e validação do modelo. O método é embasado nas proposições de Paris, Drogué e Anania (2011), que desenvolvem um modelo de calibração de comércio. Os autores utilizam as especificações dos trabalhos de Samuelson (1952) e Takayama e Judge (1964, 1971), introduzindo, nas formulações de programação matemática, uma variável de ajuste para as soluções dos problemas de otimização. 


\subsection{Custos de Transações Comerciais no Modelo PCM}

O método de Paris, Drogué e Anania (2011), baseado em Samuelson (1952) e Takayama e Judge (1964, 1971), consiste em gerar uma variável de ajuste para os problemas de programação matemática. De acordo com os autores, as especificações de programação matemática em geral exibem diferenças entre os resultados estimados e os dados observados de oferta, demanda e fluxo de comércio entre os países. Tais diferenças podem ser atribuídas à imprecisão dos custos que ocorrem nas transações comerciais ou das medidas dos parâmetros das funções de oferta e demanda, ou por ambos os motivos. A utilização do modelo sem a correção de tais diferenças pode resultar avaliações distorcidas de políticas.

O modelo desenvolvido pelos autores é adaptado ao PCM deste estudo. No método original, Paris, Drogué e Anania (2011) utilizam o primal-dual, calculado com base nas condições de KKT. Os resultados obtidos através do modelo utilizado pelos autores são exatamente iguais ao PCM, possibilitando tal adaptação. As estimativas são obtidas através de duas fases de PCM.

$\mathrm{Na}$ primeira fase, são estimados os custos das transações comerciais, ${ }^{7}$ as quantidades e os preços de oferta e de demanda, as quantidades do fluxo comercial e os custos de transportes. A variável dos custos das transações comerciais entre a região produtora $i$ e consumidora $j$ é endógena ao modelo e é definida como . A expressão matemática do PCM na primeira fase, para a obtenção da variável de custos das transações comerciais, é dada por:

$$
\begin{array}{lll}
\sum_{j}^{J} X_{i, j} \leq q_{i}^{s} & \varphi_{i} \geq 0 & {\left[q_{i}^{s}-\sum_{j}^{J} X_{i, j}\right] \varphi_{i}=0} \\
q_{j}^{d} \leq \sum_{i}^{I} X_{i, j} & \lambda_{j} \geq 0 & {\left[\sum_{i}^{I} X_{i, j}-q_{j}^{d}\right] \lambda_{j}=0} \\
X_{i, j}=\bar{X}_{i, j} & \gamma_{i, j}=\text { livre } & {\left[X_{i, j}=\bar{X}_{i, j}\right] \gamma_{i, j}=0}
\end{array}
$$

$\lambda_{j} \leq \varphi_{i}+t_{i, j}+\gamma_{i, j} \quad X_{i, j} \geq 0 \quad\left(\gamma_{i, j}+\left(t_{i j}+\varphi_{i}\right)\left(1+\operatorname{tar}_{i, j}\right)+S_{i}-\lambda_{j}\right) X_{i, j}=0$

$7 \quad$ A variável custo de transações comerciais inclui todos os custos de comercialização existentes entre duas regiões menos os custos de transporte e tarifários. Por exemplo, incluem outros custos, como resultado de corrupção, burocracia, contrabando, perdas de mercadorias, ineficiência no sistema de logística, custos de crédito e subsídios não declarados. 
A equação 4 demonstra que, quando o preço de mercado ao produtor, que é representado pelo preço-sombra $\varphi_{i}$, for igual à zero, a soma total comercializada do país $i$ para o país j será menor que a quantidade ofertada pelo país $i$. Entretanto, se o preço que os produtores desejam receber for maior do que zero, então o volume total comercializado do país $i$ para o país $j$ será igual à quantidade ofertada no país $i$. De acordo com a equação 5 , quando o preço de mercado ao consumidor, representado pelo preço-sombra $\lambda$, for igual a zero, a soma total comercializada do país $i$ para o país $j$ será maior que a quantidade demandada pelo país $j$. Porém, se o preço que os consumidores desejam pagar for maior do que zero, então o volume total comercializado do país $i$ para o país $j$ será igual à quantidade demandada no país $j$. A equação 6 representa o fluxo do comércio entre as regiões $i$ e $j$, dado pela relação de igualdade entre o fluxo observado e o fluxo estimado. Essa é a parte do sistema de equações que permite estimar uma medida para os custos das transações, $\gamma_{i, j}$.

A equação 7 determina os fluxos comerciais entre as regiões associando aos diferenciais de preços e levando em consideração os custos de transporte, subsídios, tarifas e custos das transações comerciais. Essa equação implica, no caso em que os fluxos comerciais de uma determinada região $i$ para uma região $j$ sejam maiores do que zero, que o preço do produto na região consumidora j será resultado da combinação do preço na região produtora $i$, subsídios concedidos, custos de transporte da região $i$ para $j$, custos de transação comercial e tarifa imposta sobre as importações originárias da região $i$.

Por fim, a variável custos das transações comerciais é a única no modelo que pode assumir valores positivos ou negativos (livre). Os valores negativos podem ocorrer, de acordo com Paris, Drogué e Anania (2011), devido ao efeito de políticas de comércio como, por exemplo, os subsídios, que, quando são mais elevados que os custos das transações comerciais, tornam essa variável negativa. As variáveis positivas são condicionadas por inequações e as variáveis livres, por equações, conforme Ferris e Munson (2000).

A condição de complementaridade dada pela equação 7 determina que o preço de mercado da região de demanda $j\left(\lambda_{j}\right)$ deve ser menor que o preço de oferta da região $i\left(\varphi_{i}\right)$ a crescido dos custos de levar a mercadoria até a região de demanda $\left(t_{i, j}\right)$, dos custos das transações comerciais $\left(\gamma_{i, j}\right)$, dos subsídios e do percentual de tarifa correspondente ao produto, que depende das políticas de cada país. Se essa soma ultrapassar o preço de mercado da região $j$, o fluxo comercial do produto da região de oferta $i$ para a região de demanda $j$ não se efetivará. Assim, a condição na qual a soma dos preços e custos ultrapassa a disposição a pagar do consumidor deve levar a uma tendência de redução do comércio, ou seja, custos excessivamente altos podem restringir o fluxo comercial entre as regiões e/ou países.

Na segunda fase do problema, a variável dos custos das transações comerciais gerados na primeira fase é introduzida no modelo. Nessa fase, essa variável 
é considerada exógena. Desse modo, são estimadas as quantidades e preços de oferta e de demanda, ou seja, a quantidade de fluxo comercial passa a ser variável endógena. As expressões matemáticas do PCM na segunda fase são idênticas às da segunda fase, a exceção da equação 7, a qual passa a ser substituída pela 8, pois agora passa a ser exógeno $\hat{\gamma}_{i, j}$ :

$\lambda_{j} \leq \varphi_{i}+t_{i, j}+\gamma_{i, j} \quad X_{i, j} \geq 0 \quad\left(\hat{\gamma}_{i, j}+\left(t_{i j}+\varphi_{i}\right)\left(1+\operatorname{tar}_{i, j}\right)+S_{i}-\lambda_{j}\right) X_{i, j}=0$

A solução ótima é obtida a partir da convergência das equações complementares 4, 5 e 8 nessa segunda fase. A partir dos resultados obtidos nessa fase, podem ser criados os cenários base e alternativos.

Neste estudo, o primeiro cenário é simulado com a eliminação dos custos das transações comerciais, mantendo constantes as tarifas e os subsídios. Certamente, não existe um comércio sem esses custos, já que alguns são inerentes e inevitáveis nas transações comerciais, como, por exemplo, arbitragem no mercado financeiro de commodities ou seguro de transporte. Porém, o intuito é avaliar os impactos em potencial que os custos das transações representam no comércio internacional. No segundo cenário, os custos são mantidos e é feita uma simulação de livre-comércio. Esse desdobramento tem o objetivo de fazer uma comparação entre o grau de influência dos instrumentos tradicionais das tarifas e dos subsídios com os custos das transações comerciais no mercado externo da soja.

No terceiro e último cenário, é atribuído um choque de demanda de $20 \%$ sobre o consumo mundial. Esse percentual (acumulado) é embasado na elevação do consumo da soja e de seus subprodutos entre 2009 e 2011 , que foi de aproximadamente $18 \%$ para o grão, $15 \%$ para o óleo, $14 \%$ para o farelo de soja, conforme dados da Food and Agriculture Organization of the United Nations (FAOSTAT, 2014), e 36\% para o biodiesel, conforme a U.S. Energy Information Administration (EIA, 2013), resultando em um aumento médio dos produtos derivados da oleaginosa próximo dos $20 \%$. O objetivo desse cenário é avaliar os efeitos da elevação do consumo nos mesmos patamares do período estudado frente aos custos que incidem nas transações comerciais e das políticas comerciais no mercado internacional da soja. As simulações foram realizadas com o uso do General algebraic modelling system (Gams), através do solver "path". A seguir, são apresentados os dados utilizados neste estudo.

\subsection{Base de Dados}

Os dados utilizados neste estudo para a quantidade de demanda e oferta e para os preços da soja foram extraídos da Food and Agriculture Organization of the United Nations (FAOSTAT, 2014), para os quais é utilizada a média dos anos 
de 2009 a 2011. O uso de médias justifica-se pela necessidade de minimizar as variações de mudanças abruptas na economia. A quantidade consumida é formada pela soma da produção e importação, excluídas as quantidades de exportação. As elasticidades ${ }^{8}$ de oferta e de demanda da oleaginosa são obtidos da Food and Agricultural Policy Research Institute (FAPRI, 2014).

Os custos de transporte foram calculados a partir de informações da Organização para a Cooperação e Desenvolvimento Econômico, referente ao ano de $2007^{9}$ (OECD, 2013b). As distâncias entre os países são dadas em milhas náuticas e foram cedidas pela pesquisadora Ileana Cristina Neagu, do Banco Mundial, Washington-DC em 2002, conforme Alvim (2003). Os subsídios também foram extraídos da OECD (2013a) e representam a transferência do governo para o produtor em dólar por toneladas de soja. Todos os valores de transferências foram convertidos em dólares. As tarifas de importação são ad valorem e foram coletadas da Organização Mundial do Comércio (OMC, 2013). Tanto os custos de transportes extraídos da OECD, quanto as tarifas extraídas da OMC referem-se ao método internacional de classificação Sistema Harmonizado (SH) da tabela de Nomenclatura Comum do Mercosul (NCM) de código 120100, que inclui a soja para semeadura e outros grãos de soja. O fluxo do comércio entre os países é representado pelas exportações líquidas da soja, que é calculado pela diferença entre as exportações e importações para cada país. Os dados foram extraídos da United Nations commodity trade statistics database (UN COMTRADE, 2013) e agregados conforme as regiões selecionadas para o estudo. Na próxima seção, são apresentados os resultados dos cenários base e alternativos.

\section{Resultados}

Inicialmente, são apresentados os resultados produzidos pelo modelo na primeira fase referentes à calibração do modelo e à geração dos custos das transações comerciais. Em seguida, são apresentados os cenários base e alternativos, que fazem parte da segunda fase da produção dos resultados.

\subsection{Calibração do Modelo e Custos das Transações Comerciais}

A primeira fase do modelo é o momento em que os custos de transação são estimados juntamente com os preços de equilíbrio de mercado (preço-sombra), a partir dos dados observados (reais). A variável estimada representa os custos que

\footnotetext{
8 No PCM, os coeficientes de elasticidades são incluídos nas restrições das equações 4 e 5, substituindo as quantidades produzidas e consumidas pelas seguintes expressões: e .

92007 é o último ano de disponibilidade dos dados para os custos de transporte da soja pela OECD.
} 
ocorrem nas transações comerciais de forma agregada e servem para fazer a calibração do modelo (PARIS et al., 2011).

O objetivo da etapa de calibração é corrigir possíveis distorções ocorridas entre os dados observados e estimados. Os resultados que equivalem à situação real (valores observados) confirmam a adequação dos coeficientes e da estrutura do modelo. Nesse sentido, observa-se que o modelo estimado representa adequadamente o mercado internacional da soja para os países selecionados quanto as seguintes variáveis: produção, consumo, exportações e preços. Para todas essas variáveis, a diferença entre os valores observados e estimados é zero, o que mostra a validade do modelo.

Nessa etapa, também são calculados os custos das transações comerciais, apresentados na Tabela 3, em ordem decrescente de valor. Há casos em que os custos das transações comerciais ocorrem com valores negativos, como, por exemplo, na exportação dos Estados Unidos para o resto mundo. Vale lembrar que o fenômeno pode ocorrer devido ao efeito de políticas de comércio, como, por exemplo, quando os subsídios concedidos são mais elevados que os demais custos comerciais.

Tabela 3 - Custos das transações comerciais no mercado internacional da soja para regiões selecionadas (2009-2011)

\begin{tabular}{lcc|ccc}
\hline \multicolumn{2}{c}{ Países } & $\begin{array}{c}\text { Custo das } \\
\text { transações }\end{array}$ & \multicolumn{2}{c}{ Países } & $\begin{array}{c}\text { Custo das } \\
\text { transações }\end{array}$ \\
\hline Exportador & Importador & US\$/t & Exportador & Importador & US\$/t \\
\hline Brasil & União Europeia & 50 & Argentina & Resto do mundo & 19 \\
Argentina & União Europeia & 49 & Brasil & Resto do mundo & 18 \\
Argentina & China & 39 & Brasil & Argentina & 4 \\
Brasil & China & 39 & Estados Unidos & Resto do mundo & -1 \\
Estados & União Europeia & 34 & Resto do mundo & União Europeia & -6 \\
Unidos & Estados Unidos & 26 & Resto do mundo & China & -13 \\
Brasil & China & 26 & Resto do mundo & Estados Unidos & -34 \\
Estados & Unidos & & & & \\
\hline
\end{tabular}

Fonte: Elaboração própria a partir das estimativas geradas pelo modelo.

As exportações do Brasil e da Argentina para a UE e para a China possuem os maiores custos de transação. Os custos dos países latinos são respectivamente de US\$ 50 e US\$ 49 por tonelada de soja para exportar para a UE e de US\$ 39 para ambos para enviar a soja para a China. As exportações dos Estados Unidos para a UE têm custos de US $\$ 34$ e para a China de US $\$ 26$. Os menores custos são para as exportações da Argentina (US\$ 19) e do Brasil (US\$18) para o resto do mundo.

Todavia, todos os fluxos de comércio com regiões do resto do mundo devem ser analisados com cautela, pois representa uma agregação de vários países e con- 
sidera um custo de transporte, tarifa e subsídio que buscam representar um comportamento médio de uma região com países heterogêneos. Nesse sentido, para esse caso, os custos de transação têm como principal objetivo fazer o fechamento do modelo de maneira que ocorra o melhor ajuste do cenário base (estimado) aos valores observados em termos de produção, consumo e exportações de soja. Os cenários base e alternativos são apresentados a seguir.

\subsection{Cenário Base e Alternativos}

Os resultados da segunda fase do modelo geram o cenário base que serve como referência para os cenários alternativos. Em todos os cenários, utilizam-se as mesmas variáveis do comércio apresentadas até o momento. Para se testar a validade das estimativas do cenário base, os dados são confrontados com os resultados obtidos na primeira fase. A Tabela 4 mostra as quantidades e preços de oferta e de demanda após a calibração do modelo com a introdução dos custos das transações comerciais estimados.

Tabela 4 - Valores estimados (primeira fase) e o cenário base para quantidades e preços no mercado internacional da soja (2009-2011)

\begin{tabular}{|c|c|c|c|c|c|c|c|c|c|}
\hline \multirow[b]{2}{*}{ Países } & \multicolumn{3}{|c|}{ Quantidade de oferta } & \multicolumn{3}{|c|}{ Quantidade de demanda } & \multicolumn{3}{|c|}{ Preços } \\
\hline & $\begin{array}{l}1^{a} \text { fase } \\
(\mathrm{mil} \mathrm{t})\end{array}$ & $\begin{array}{c}\text { Cenário } \\
\text { base } \\
\text { (mil t) }\end{array}$ & $\begin{array}{c}\text { Variação } \\
\text { (\%) }\end{array}$ & $\begin{array}{l}1^{a} \text { fase } \\
(m i l ~ t)\end{array}$ & $\begin{array}{c}\text { Cenário } \\
\text { base } \\
\text { (mil t) }\end{array}$ & $\begin{array}{c}\text { Varia- } \\
\text { ção } \\
\text { (\%) }\end{array}$ & $\begin{array}{c}1^{a} \text { fase } \\
\text { (US\$/t) }\end{array}$ & $\begin{array}{c}\text { Cenário } \\
\text { base } \\
\text { (US\$ /t) }\end{array}$ & $\begin{array}{c}\text { Variação } \\
\text { (\%) }\end{array}$ \\
\hline Argentina & 44.171 & 44.188 & 0,01 & 34.887 & 34.884 & $-0,01$ & 419 & 419 & 0,00 \\
\hline Brasil & 66.972 & 66.971 & 0,00 & 36.851 & 36.852 & 0,00 & 425 & 425 & 0,00 \\
\hline Estados Unidos & 88.739 & 88.737 & 0,00 & 50.081 & 50.100 & 0,01 & 454 & 454 & 0,00 \\
\hline União Europeia & 1.141 & 1.141 & 0,00 & 13.977 & 13.990 & 0,01 & 480 & 480 & 0,00 \\
\hline China & 14.838 & 14.853 & 0,02 & 66.988 & 66.997 & 0,01 & 490 & 490 & 0,00 \\
\hline Resto do mundo & 33.631 & 33.640 & 0,03 & 46.708 & 46.709 & 0,00 & 479 & 479 & 0,00 \\
\hline
\end{tabular}

Fonte: Elaboração própria a partir das estimativas geradas pelo modelo.

Conforme descrito na metodologia, no cenário base são incluídos, além dos custos de transporte, tarifas e subsídios, os custos de transação calculados na primeira fase e apresentados na Tabela 3. Como resultado dessas diferenças de custos de comercialização e de produção entre as regiões analisadas, a Tabela 4 apresenta os diferentes preços de soja no cenário base. A Argentina e o Brasil destacam-se com os menores preços internacionais, 419 e 425 dólares por tonelada, respectivamente (ver Tabela 4).

As vantagens comparativas da Argentina e do Brasil em relação aos Estados Unidos existem principalmente em função da elevada produtividade e dos menores custos de produção. A exemplo disso, Nardi e Davis (2007) mostram que os custos de produção da soja são de 124,17 dólares por tonelada para o Paraná 
(Brasil), 132,70 para o Mato Grosso (Brasil), 133,20 para Santa Fé (Argentina) e 250,20 para Iowa, nos Estados Unidos.

Os percentuais exibidos na Tabela 4 mostram que a distribuição das variáveis e os valores permanecem praticamente os mesmos estimados na primeira fase com pequenas diferenças, como pode ser observado. Os valores do cenário base servem de parâmetro de medida para os cenários alternativos, cujos resultados são apresentados a seguir.

A Tabela 5 retrata o primeiro cenário, que simula a eliminação dos custos das transações comerciais. Com a eliminação dos custos, a Argentina e o Brasil elevam suas produções em 1,37\% e 1,17\% e os preços em 4,30\% e 3,53\%, respectivamente. O aumento da produção e dos preços na Argentina e no Brasil é reflexo do aumento das exportações, estimuladas pela redução dos custos de transação comercial com seus parceiros. 


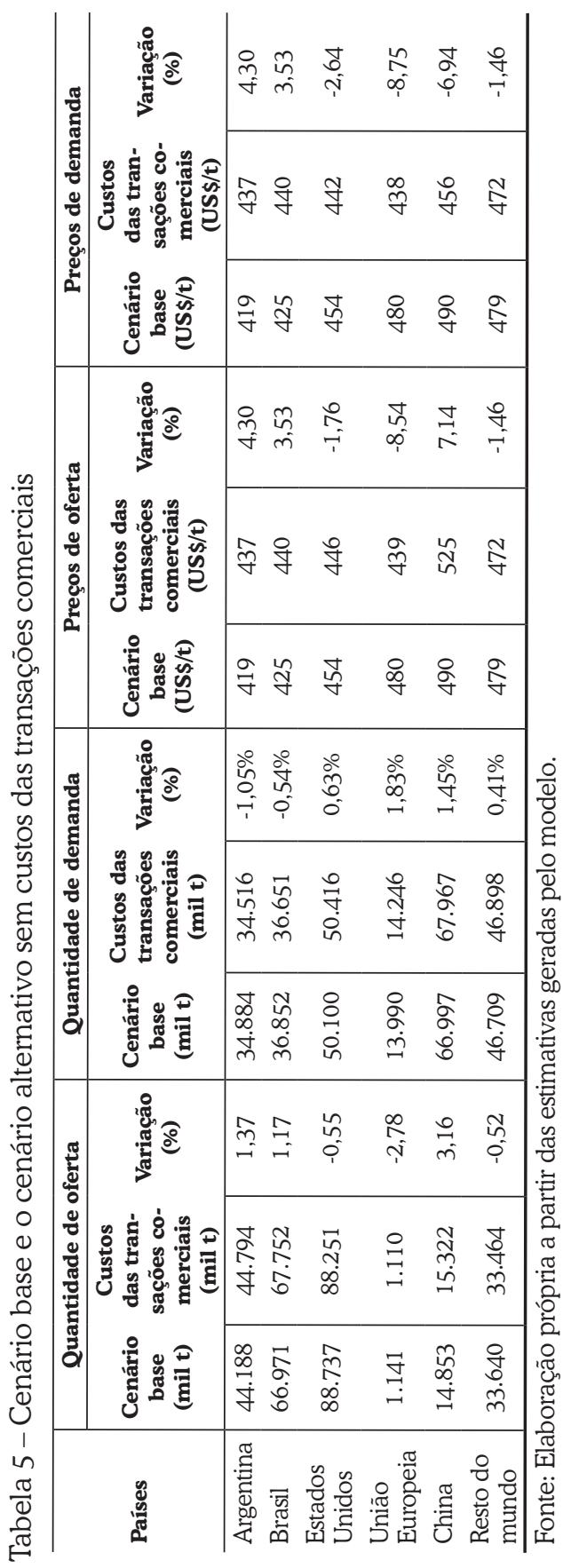

Análise Econômica, Porto Alegre, v. 38, n. 77, p. 81-108, set. 2020. 
As informações do primeiro cenário mostram que em tal situação as quantidades de oferta apresentam os maiores impactos para a China, que registra aumento de $3,16 \%$, e para a UE, que reduz em 2,78\%. Os Estados Unidos e o resto do mundo apresentam os menores impactos, registrando redução de 0,55\% e 0,52\%, respectivamente. Os preços de oferta apresentam os maiores impactos para a China, com elevação de 7,14\%, e para a UE, com redução de $8,54 \%$. Os preços de demanda mantêm praticamente a mesma trajetória e os mesmos percentuais dos preços, com exceção da China, que passa a apresentar uma redução de preços de 6,94\%.

Esse cenário mostra que os países que apresentam aumento na oferta da soja são aqueles que possuem os maiores custos das transações comerciais, a China, o Brasil e a Argentina, conforme as estimativas da primeira fase. Já em termos de consumo, a China e a UE destacam-se com os maiores aumentos na quantidade de demanda e na redução dos preços.

Para a Argentina e o Brasil (exportadores), as causas prováveis, por hipótese, dos maiores custos de transações comerciais estão associadas a problemas nos países de origem, como burocracia, corrupção e incertezas quanto à estabilidade nas regras e contratos (BATISTA, 2008). Com relação aos custos de transação da China e da UE (importadores), identifica-se pelo menos duas possibilidades para os maiores custos de transação nas importações para esses destinos: a necessidade de rotulagem de produtos transgênicos nos países da UE e a elevada concentração de fretes marítimos nos períodos de safra para a China.

No caso da China, são identificados que os maiores custos estimados de transação comercial estão associados às variações nos custos de frete e à corrupção. No frete marítimo, há variações nos custos devido às flutuações da demanda na China, que é o maior país importador de soja (cerca de 60\% do comércio mundial). Em épocas de alta demanda por navios, há congestionamentos nos portos, reduzindo o volume de negócios dos navios e aumentando os custos do frete (LOPEZ; RAMOS; SIMKIEVICK, 2008). Assim, os custos das transações comerciais para esse destino podem estar relacionados com o padrão do comércio de soja com um número limitado de países produtores e um comércio muito concentrado.

Em particular, em relação aos países da UE, deve ser analisada a legislação europeia em matéria de rastreabilidade e rotulagem dos produtos geneticamente modificados, que entrou em vigor em 2004. Alguns estudos, como os de Wilkinson (2005), Disdier e Fontagné (2010) e Oliveira, Silveira e Alvim (2012), salientam que a legislação europeia que regulamenta o comércio de Organismos Geneticamente Modificados (OGM) exige a rastreabilidade e rotulagem de todos os gêneros alimentícios e alimentos para animais derivados de geneticamente modificados. Essa legislação, por sua vez, estimulou a segregação entre a soja geneticamente modificada e a soja convencional, o que pode explicar os altos custos de transação comercial com destino para os países da UE, considerando as características regulatórias da zona de destino. 
Dessa forma, esse primeiro cenário sinaliza a importância de políticas voltadas para a melhoria da redução dos custos de transação comercial. Particularmente, em relação ao Brasil, os custos de transação, possivelmente, por hipótese, são relacionados a problemas como a estrutura de transporte, estradas, procedimentos de fronteiras e portos. Esses podem se constituir em restrição ao aumento da participação das exportações de soja.

Em condições de livre-comércio (cenário 2), os países do resto do mundo, os países da UE, a Argentina e o Brasil se destacam com os maiores aumentos na produção e no consumo, conforme Tabela 6. No caso dos Estados Unidos, ocorre uma queda na produção e um aumento no consumo de soja. Por sua vez, a UE tem suas importações reduzidas em relação ao cenário base, principalmente em função da redução das exportações americanas (Tabela 6). Os preços de oferta se elevam em todas as regiões, com exceção dos Estados Unidos, que apresentam uma queda de $0,22 \%$. Os preços de demanda registram os maiores impactos para a Argentina e o Brasil, com queda de $5,25 \%$ e 4,94\%, respectivamente, para cada país. 


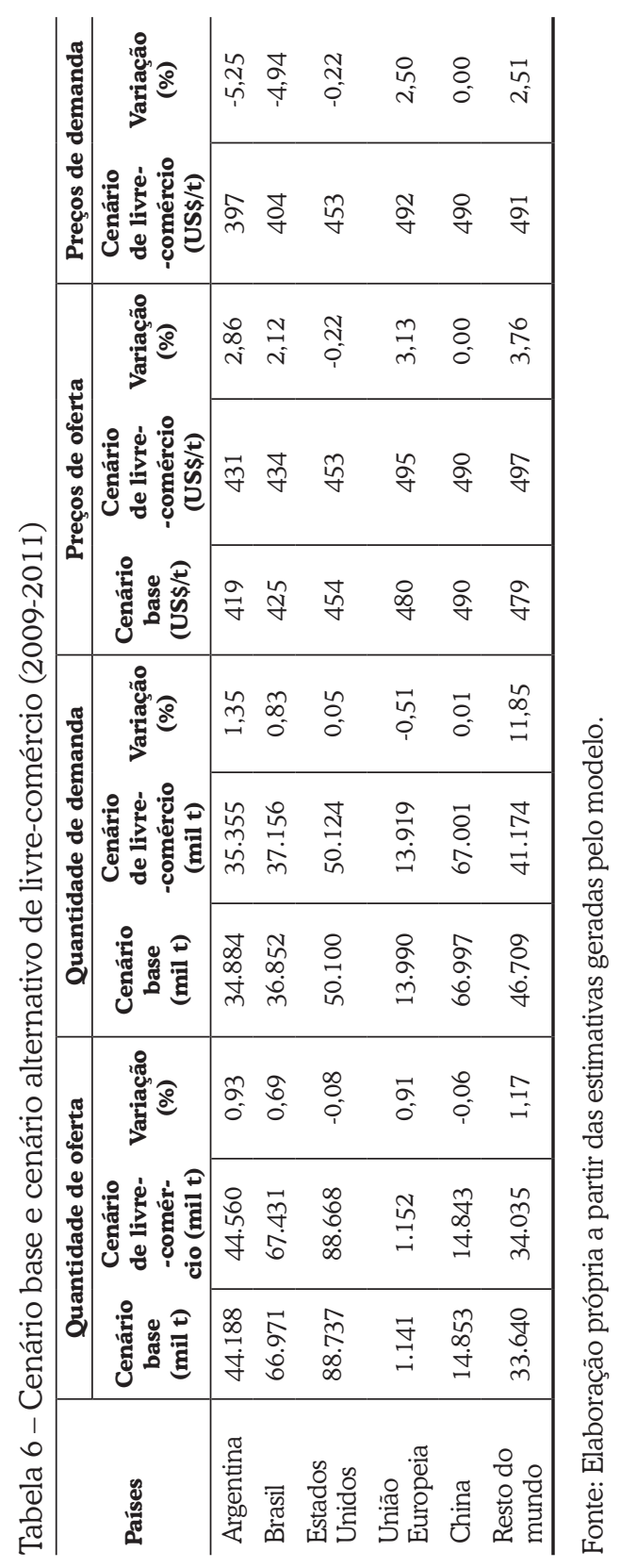


De uma forma geral, os produtores dos Estados Unidos e da China têm perdas nesse cenário, mas que podem ser parcialmente compensadas pelos ganhos dos consumidores. Já a UE, importadora de soja, nesse mesmo cenário tem ganhos para os produtores, que superam as perdas dos consumidores.

Para o Brasil e a Argentina, com o livre-comércio, existem ganhos potenciais para os produtores e consumidores. Embora os Estados Unidos não imponham barreiras tarifárias para proteger seu mercado de soja, a subvenção de subsídios para a produção de soja contribui para reduzir os preços internacionais do produto. Por sua vez, esse efeito sobre os preços internacionais se reflete na produção e no consumo da Argentina e do Brasil, os quais, conforme os resultados, são os maiores prejudicados com as políticas protecionistas americanas.

A Tabela 7 exibe o terceiro cenário: choque da demanda na presença dos custos de transação comercial e com as tarifas e os subsídios. Todos os países aumentam a oferta, mas a China é o que mais aumenta a oferta de soja, com 14,90\%. O Brasil apresenta as maiores variações no consumo (13,62\%) em relação às demais regiões, seguido pela UE e pela China. 


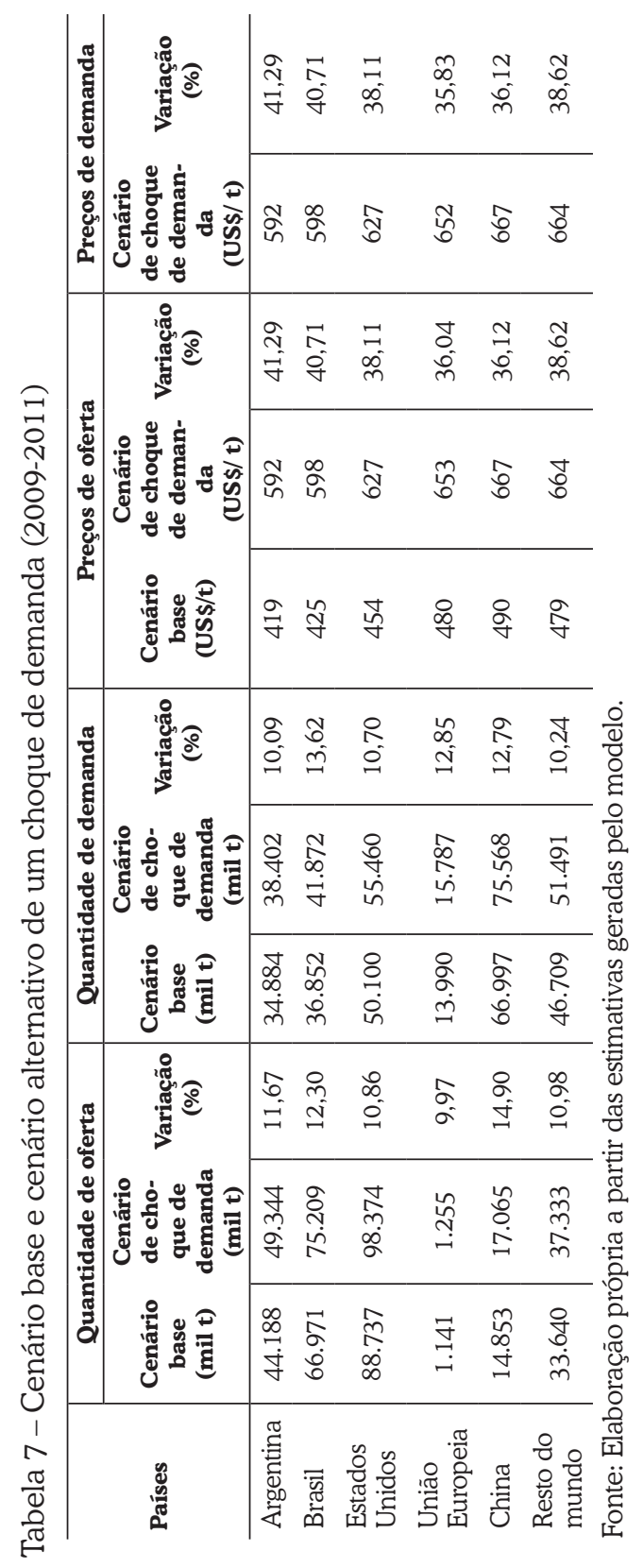


A Argentina sofre os maiores aumentos nos preços da oferta e demanda com 41,29\%. A UE apresenta o menor aumento na produção de oleaginosas, com $9,97 \%$, e também nos preços da oferta e da procura, com $36,04 \%$ e $35,83 \%$, respectivamente.

Com a simulação de um aumento de $20 \%$ no consumo mundial (mesmo ritmo de crescimento acumulado do consumo de soja entre 2009 e 2011), e ao manter o mesmo nível dos custos de transação comercial e as mesmas políticas comerciais adotadas, o Brasil e a UE são as únicas regiões que não são favorecidas com um aumento na produção superior ao consumo. As demais regiões, incluindo o resto do mundo, elevam a produção em uma proporção maior do que o consumo.

Em termos gerais, observa-se que o cenário mais favorável para o produtor de soja é o de aumento da demanda por soja e derivados (ver Tabela 7), ainda que não eliminados as barreiras comerciais, subsídios e custos das transações comerciais considerados no estudo. Por fim, os três cenários demonstram que o mercado da soja reage diferentemente e de acordo com as peculiaridades de cada região estudada.

\section{Considerações Finais}

O estudo sugere a importância de políticas direcionadas à melhoria da redução dos custos de transação comercial. Para o Brasil e a Argentina, as principais restrições podem ter origem na burocracia, corrupção, incerteza relativa à estabilidade das regras e cumprimento de contratos. A UE pode ter seus custos mais elevados devido à legislação de rastreabilidade e rotulagem para transgênicos. Já para as exportações chinesas, os custos podem ser devido a problemas de corrupção e as variações nos custos dos fretes pela elevada demanda por navios (congestionamentos nos portos), maior ociosidade dos navios no retorno do destino e, consequentemente, um aumento nos custos dos fretes.

Especificamente para o Brasil, os custos de transação estão possivelmente relacionados a problemas como a estrutura de transporte, procedimentos de fronteiras e portos, os quais podem servir de restrição ao aumento da participação das exportações de soja. Diante dos mesmos níveis de consumo de soja do mundo no período de análise, o Brasil corre o risco de perder o mercado para países como a Argentina devido, por exemplo, ao atraso no prazo de entrega dos grãos. Assim, a importância do planejamento na estrutura de saída da soja brasileira é enfatizada no que diz respeito ao acompanhamento dos níveis no aumento da oferta de soja.

De uma forma geral, os impactos dos custos das transações comerciais no mercado da soja diferem entre as regiões em termos de intensidade e direção quando comparados com os efeitos da eliminação de tarifas e subsídios. Com o livre-comércio, os efeitos são contrários, menos intensos e ocorrem devido às barreiras tarifárias e ao tipo de subsídio concedido aos produtores, ou seja, que dependem da política agrícola e comercial de cada região. 
Para o caso da Argentina e do Brasil com o cenário de livre-comércio, a produção e as exportações de soja são favorecidas, resultando em um maior preço concedido aos produtores dessa região. Isso ocorre principalmente em função da eliminação dos subsídios americanos e chineses, que distorcem o mercado internacional de soja.

Conforme comentado anteriormente, os produtores americanos e chineses apresentam perdas no cenário de livre-comércio, embora sejam reduzidas. Em termos gerais, essas perdas são compensadas parcialmente pelos ganhos dos consumidores. Os Estados Unidos e a China são os países que mais concedem subsídios ao mercado de soja. No caso do primeiro, embora existam tarifas reduzidas, os subsídios são baseados em pagamentos à produção e contribuem para reduzir os preços internacionais através de um estímulo ao aumento da produção. Por outro lado, no caso da China, os subsídios da soja são concedidos ao consumidor através de uma política de suporte aos preços de mercado. Em média, os subsídios aplicados ao mercado americano e chinês equivalem a US $\$ 15$ por tonelada e US\$ 21 por tonelada, respectivamente.

Nesse cenário de livre-comércio é possível observar os efeitos das diferentes estratégias comerciais dos países analisados no mercado de soja internacional. Especificamente, com relação aos principais países exportadores (Estados Unidos, Brasil e Argentina), existe uma relativa menor proteção de mercado no caso dos países latino-americanos do que no caso dos norte-americanos. Isso pode ser confirmado na medida em que, no cenário de livre-comércio, os maiores beneficiados são os produtores argentinos e brasileiros e os maiores prejudicados, os produtores de soja americanos. Dessa forma, este estudo reforça os efeitos negativos do protecionismo americano sobre os países em desenvolvimento, como, por exemplo, a Argentina e o Brasil.

Já a simulação de um choque de demanda no mercado da soja permite sugerir que os ganhos dos produtores de soja nos últimos anos, decorrentes da maior demanda pelo produto, compensaram significativamente as perdas decorrentes da ineficiência nos sistemas de comercialização (maiores custos de transação comercial) e dos atrasos nas negociações de livre-comércio. Para o cenário de choque de demanda, a maior parte das regiões apresentam um incremento na produção superior ao consumo, com exceção do Brasil e da UE.

Dessa forma, o estudo sugere a importância de políticas direcionadas para a redução dos custos das transações comerciais para o Brasil, a Argentina e a China. De acordo com este estudo, diante do aumento de $20 \%$ no consumo, mesma taxa de crescimento acumulado do período de análise, os custos das transações comerciais, que estão relacionados a problemas como estrutura de transportes, estradas, procedimentos de fronteiras e portos, podem servir de entraves para um aumento da participação das exportações da soja brasileira no mercado mundial.

O estudo permite, além da contribuição empírica detalhada a partir dos resultados de cada cenário alternativo, uma contribuição metodológica. O trabalho 
de Paris, Drogué e Anania (2011) desenvolve matematicamente a calibragem de modelos de equilíbrio parcial incluindo a variável de custos de transação comercial, todavia sem desenvolver um modelo empírico que analise um mercado específico. A contribuição metodológica deste trabalho está na modelagem do modelo de equilíbrio parcial no Gams incluindo os custos de transação como uma variável que permite a calibragem ou o fechamento do modelo no cenário base.

Todavia, essa modelagem apresenta limitações em relação à agregação dos custos das transações comerciais e dos fluxos de comércio. No primeiro caso, não existe a possibilidade de desagregação por tipos de custos, como, por exemplo, os custos do mercado financeiro ou de contratos e de seguros; no segundo, não é possível estimar a variação da participação e do direcionamento individual das exportações e importações dos países. Em ambos os casos, as restrições estão relacionadas às limitações do modelo, dificultando saber quais os custos que efetivamente formam os custos das transações comerciais e a visualização da dinâmica comercial com as possiveis alterações provocadas pelo impacto dos custos das transações, da condição de livre-comércio e do choque de demanda em cada região.

Além disso, existem outras limitações referentes ao recorte em termos de cenários alternativos que não incluem outras possíveis mudanças. Entre estas estão, por exemplo, os efeitos de mudanças na taxa de câmbio sobre os preços ao produtor, mudanças nos estoques de soja e nos preços relativos de farelo e óleo de soja e de possíveis efeitos de mudanças nos preços da soja decorrentes de especulação financeira.

\section{Referências}

ALVIM, A. M. Os impactos dos novos acordos de livre comércio sobre o mercado de arroz no Brasil: um modelo de alocação espacial e temporal. 2003. Tese (Doutorado em Economia) - Faculdade de Ciências Econômicas, Universidade Federal do Rio Grande do Sul, Porto Alegre, 2003.

ALVIM, A. M. As consequências dos acordos de livre comércio sobre o setor de lácteos no Brasil. Revista de Economia e Sociologia Rural, v. 48, n. 2, p. 406-427, 2010.

ALVIM, A. M.; WAQUIL, P. D. O problema de complementaridade mista: um modelo de alocação espacial aplicado ao setor agrícola. In: SANTOS, M. L.; VIEIRA, W. C. Métodos quantitativos em economia. Viçosa: UFV, 2004, p.161-190.

ARBIX, D. A. Pacificação do comércio internacional? A participação dos países em desenvolvimento nos contenciosos da OMC. Revista Jurídica, v. 8, n. 83, p.149-167, 2007.

BATISTA, J. C. The transport costs of Brazil's exports: a case study of agricultural machinery and soybeans. Int Working Paper - IDB, n. 12, 2008. Disponível em: http://publications.iadb. org/handle/11319/2510?locale-attribute=pt. Acesso em: 30 jun. 2015. 
BISHOP, P. M.; NICHOLSON, C. F.; PRATT, J. E. Tariff-Rate quotas: difficult to model or plain simple? NZIER Working Paper, n. 2001/7, 2001. Disponível em: https://nzier.org.nz/publication/tariff-rate-quotas-difficult-to-model-or-plain-simple. Acesso em: 15 dez. 2002.

CAIXETA FILHO, J. V.; SOARES G. M. Caracterização do mercado de fretes rodoviários para produtos agrícolas. Gestão e Produção, v. 4, n. 2, p. 186-204. 1997.

DISDIER, A. C.; FONTAGNÉ, L. Trade impact of european measures on GMOs condemned by the WTO panel. Review of World Economics, v. 146, n. 3, p. 495-514, 2010.

EIA. U.S. Energy Information Administration. Washington, 2013. Disponível em: http://www. eia.gov/beta/international/. Acesso em: 30 jun. 2014.

FAOSTAT. Food and Agriculture Organization of the United Nations. Roma, [2014]. Disponível em: http://faostat.fao.org. Acesso em: 30 jun. 2014.

FAPRI (Food and Agriculture Policy Research Center). Elasticities databases. FAPRI, Colúmbia, 2014. Disponível em: https://www.fapri.missouri.edu/ Acesso em: 21 ago. 2014.

FERNANDES, L. A; CRUZ, L. B.; PEDROZO, E. A.; SCHMIDT, P.; SANTOS, J. L. Respeito à norma, protecionismo ou oportunismo: uma análise da tomada de decisão chinesa no caso da soja brasileira. FACEF Pesquisa, v. 8, n. 3, p. 61-76, 2005.

FERRIS, M. C.; MUNSON, T. S. GAMS/Path user Guide, version 4.3. Washington, D.C: GAMS Development Corporation, 2000. p. 5-33.

FIGUEIREDO, A. M et al. Impactos dos subsídios agrícolas dos Estados Unidos na expansão do agronegócio brasileiro. Estudos Econômicos, São Paulo, v.40, n.2, p. 445-467, 2010.

GIOVINE, H.; CHRIST, D. Estudo sobre processos de armazenagem de grãos - um estudo de caso - região de Francisco Beltrão - PR. Ciências Sociais Aplicadas em Revista - UNIOESTE, v. 10, n. 18, p. 139-152, 2010.

LÓPEZ, A.; RAMOS, D.; SIMKIEVICH, C. The impact of china's global economic expansion on Latin America: a study of the impact of china's global expansion on Argentina. World Economy 8 Finance Research Programme - Working Paper, n. 2, 2008. Disponível em: http://citeseerx.ist.psu.edu/viewdoc/download?doi $=10.1 .1 .550 .4610 \mathcal{E}$ rep $=$ rep $1 \mathcal{E}$ type $=$ pdf. Acesso em: 12 dez. 2014.

LORA, E. Should Latin America fear China? SSRN, 2004. Disponível: http://papers.ssrn.com/ sol3/papers.cfm?abstract_id=612441. Acesso em: 1 jul. 2015.

LIMAO, N.; VENABLES A. J. Infrastructure, geographical disadvantage and transport costs. The World Bank Economic Review, v. 15, n. 3, p. 451-479, 2001.

NARDI, M. G.; DAVIS, T. D. Soybean landed cost competitiveness analysis for Argentina, Brazil and United States Soybean Landed Cost Competitiveness Analysis for Argentina, Brazil and the United States. In: VI INTERNATIONAL PENSA CONFERENCE, 2007, Ribeirão Preto. Proceedings [...]. Ribeirão Preto: FEA-RP, 2007. Disponível em https://www.researchgate. net/publication/271076552. Acesso em: 10 out. 2014 . 
NOLTE, S.; BUYSSE, J.; HUYLENBROECK, G. V. Modelling the effects of an abolition of EU sugar quota on internal prices, production and imports. European Review of Agricultural Economics, v. 39, n. 1, p. 75-94, 2011.

OECD. Producer Support Estimates. OECD, 2013a. Disponível em: https://www.oecd.org/ unitedstates/producerandconsumersupportestimatesdatabase.htm. Acesso: 30 jun. 2013.

OECD. Transportation costs: statextracts. OECD, 2013b. Disponível em: http://stats.oecd.org/ Index.aspx?DataSetCode=MTC. Acesso: 30 jun. 2013.

OJIMA, A. L. R. O.; YAMAKAMI, A. Aplicação de um modelo de equilíbrio espacial de programação quadrática para questão logística da soja. Revista Gestão Industrial, v. 1, n. 3, p. 103-113, 2005.

OLIVEIRA, A. L. R.; SILVEIRA, J. M.; ALVIM, A. M. Cartagena protocol, biosafety and grain segregation: the effects on the soybean logistics in Brazil. E3 Journal of Agricultural Research and Development, v. 2, n. 1, p. 17-30, 2012.

OLIVEIRA, A. L. R. O.; SILVEIRA, J. M. F. J. Restructuring of corn supply chain in Brazil: facing the challenges in logistics or regulation on biotechnology. International Food and Agribusiness Management Review, v. 16, n. 4, p. 1-24, 2013.

OMC (Organização Mundial do Comércio). Tarifas. Genebra: OMC, [2013]. Disponível em: http://tariffanalysis.wto.org/default.aspx. Acesso em: 15 jul. 2013.

PARIS, Q., DROGUÉ, S.; ANANIA, G. Calibrating spatial models of trade. Journal of Economic Modeling, v. 28, n. 6, p. 2509-2516, 2011.

PONTES, H. L. J.; CARMO, B. B. T.; PORTO A. J. V. Problemas logísticos na exportação brasileira da soja em grão. Revista Eletrônica Sistemas $\mathcal{E}$ Gestão, v. 4, n. 2, p.155-181, 2009.

PORTO, G. G. Informal export barriers and poverty. Journal of International Economics, v. 66, n. 2, p. 447-470, 2005.

RABELO JUNIOR, T.; IKEDA, R., H. Mercados eficientes e arbitragem: um estudo sob o enfoque das finanças comportamentais. Revista Contabilidade e Finanças, v. 15, n. 34, 2004. Disponível em: http://dx.doi.org/10.1590/S1519-70772004000100007. Acesso em: 5 set. 2013.

RODRIGUES, F. R.; BURNQUIST, H. L.; COSTA, C. C. Escalada tarifária e exportações brasileiras da agroindústria do café e da soja. Revista de Economia e Sociologia Rural, v. 49, n. 2, p. 295-322, 2011.

RUTHERFORD, T. F. Extension of GAMS for complementarity problems arising in applied economic analysis. Journal of Economic Dynamics and Control, v. 19, p. 1299-1324, 1995.

RUTHERFORD, T. F. Mixed complementarity programming with Gams. Lecture Notes for Economy, n. 6433, 2002. Disponível em: http://pascal.iseg.ulisboa.pt/ depeco/summerschool2008/P1-jedc1999.pdf. Acesso em: 30 jun. 2014.

SAMUELSON, P. B. Spatial price equilibrium and linear programing. American Economic Review, v. 42, p. 283-303, 1952. 
SANDRONI, P. Dicionário de economia do século XXI. 4 ed. Rio de Janeiro: Ed. Record, 2008.

TAKAYAMA, T., JUDGE, G. Spatial equilibrium and quadratic programming. Journal of Farm Economics, v. 46, p. 67-93, 1964.

TAKAYAMA, T., JUDGE, G. Spatial and temporal price and allocation models. Amsterdam: North-Holland Publishing Company, 1971.

UN COMTRADE. United Nations Commodity Trade Statistics Database. [S. 1.], 2013. Disponível em: http://comtrade.un.org/db/. Acesso: 30 jul. 2013.

UNCTAD. UNCTAD -Trains: trade analysis and information system. Geneva: UNCTAD, 2013. Disponível em: http://www.unctad.org. Acesso: 15 dez. 2014.

USDA (United States Department of Agriculture). Foreign AgricultureService. 2011. Disponível em: https://apps.fas.usda.gov/psdonline/app/index.html\#/app/downloads. Acesso: 10 jun. 2011.

WILKINSON, J. Transgênicos e a competitividade brasileira face aos desafios de novas formas de coordenação nas cadeias de grãos. In: CONGRESSO DA SOBER, 43., 2005, Ribeirão Preto. Anais eletrônicos [...]. Ribeirão Preto: SOBER. Disponível em: https://www.researchgate.net/publication/228961550. Acesso em: 1 jul.2015.

Autor correspondente:

Augusto Mussi Alvim

E-mail: augusto.alvim@pucrs.br

Recebido em: 25/02/2016. Aceito em: 15/10/2018.

(cc) BY 